\title{
REPRESENTACIONES SOCIALES DE LA EDUCACIÓN ESCOLAR ENTRE LOS CHUJ MEXICANOS ${ }^{1}$
}

\author{
Fernando Limón Aguirre \\ flimon@ecosur.mx \\ El Colegio de la Frontera Sur \\ México
}

\section{RESUMEN}

Se comparte una lectura crítica de las representaciones sociales que los chuj mexicanos construyen en torno a la educación escolar básica, la cual tiene como núcleo central el aprender a leer y escribir, así como hablar en español. Este texto pretende ser un aporte con doble direccionalidad, por un lado para los interesados en el tema de la educación escolar básica y dentro de ellos los interesados en temas de educación intercultural o de educación indígena; y, por el otro, para quienes están preocupados por conocer el alcance de las representaciones sociales, resaltando su valor crítico.

Palabras clave: educación básica, educación intercultural, educación indígena.

\section{ABSTRACT}

This paper presents a critical reading of the social representations the Chuj people in Mexico construct around basic schooling, the core component of which is the teaching of reading and writing, as well as of speaking Spanish. This text aims to be a contribution to those interested in basic schooling, specifically those interested in intercultural education or indigenous education, as well as those interested in identifying the scope of social representations, emphasizing their critical value.

Key words: basic education, intercultural education, indigenous education. 


\section{INTRODUCCIÓN}

La educación ocupa un lugar primordial en los intereses de los colectivos sociales; así se expresa en toda serie de discursos de política pública, de programas de gobierno, de los reclamos de la sociedad organizada. La educación escolar básica es un derecho constitucional y por ende la educación básica pública debe ser garantizada en cada rincón del país, a todos los grupos sociales. La educación intercultural también es un derecho constitucional para todo el país y con mayor énfasis entre los pueblos indígenas. Sin embargo, ¿qué ocurre en cada comunidad, en cada pueblo, en las diversas regiones del país? ¿Cómo es elaborada, en el ámbito de la cognición social de los diversos colectivos sociales, la idea de la educación escolar?

El estudio de las representaciones sociales que sobre la educación escolar se construyen y circulan entre los integrantes del pueblo chuj en México es un buen ejemplo para reconocer lo que ocurre en lo que podríamos decir: un rincón del país, asumiendo que el mismo proceso de construcción singular ocurre entre cada otro rincón, entre los diversos grupos sociales; de igual manera es un buen ejemplo para reconocer el ámbito de las representaciones sociales mismas. Sabemos que éstas son construcciones sociales y que con ellas se elabora un sentido social compartido, así como que son recursos para orientarse en el contexto social, pero poco se repara en torno al sustento epistémico de las mismas y, por tanto, a su orientación y alcance. Las representaciones sociales tienen una función cognitiva y una función social. Si no se considera la manera como se construyen y el tipo de realidad social que ayudan a construir, entonces lo que se hace fácilmente es sugerir que tal realidad específica es la deseada por quienes expresan tales representaciones; asimismo, se confiere un carácter natural a las mismas desdibujando la lógica del poder presente en el contexto y por tanto los intereses ideológicos que hay detrás de tales representaciones sociales.

Esta lectura a contrapelo sobre las representaciones sociales entre los chuj pone en evidencia la ubicación y el lugar que ocupan, así como el papel que desempeñan para una construcción a modo del mundo social, en este caso en términos de la educación escolar 
básica; de igual manera pone de manifiesto las tensiones y contradicciones que conlleva la reproducción de las mismas.

En el presente artículo, se exponen las representaciones sociales que los chuj mexicanos construyen en torno a la educación escolar, la cual tiene como núcleo central el aprender a leer y escribir, así como a hablar en español. Esta representación que reproduce imágenes de injusticia social de largo cuño, contenidas en los discursos y la lógica imperante en el contexto, evidencian ciertas tensiones que emergen al contrastarse con los recursos de la memoria y la esperanza de este pueblo que se ubica en las inmediaciones de las Lagunas de Montebello, en la frontera con Guatemala, en lo que constituye una prolongación del territorio que ocupan en el país centroamericano y que en sí es parte del mismo espacio que ocupaban en tiempos precolombinos.

Este texto, por tanto, pretende ser un aporte con doble direccionalidad, por un lado para los interesados en el tema de la educación escolar y dentro de ellos los interesados en temas de educación intercultural o de educación indígena; y, por el otro, para quienes están preocupados en conocer el alcance de las representaciones sociales, pues en medio del incremento de su utilización se ha llegado a desvirtuar su valor crítico y a utilizarlas naturalizando los discursos e intereses predominantes en el contexto.

\section{MARCO TEÓRICO}

El estudio de las representaciones sociales es una propuesta que ha surgido del ámbito de la sicología social, bajo el paradigma del construccionismo social. El término designa dos aspectos teóricos, el primero se refiere a los tipos particulares de nociones sociocognitivas, cuya función es aportar los medios intersubjetivamente compartidos para la comunicación y la comprensión al interior de las colectividades; en tanto el segundo refiere al proceso por el que dichas nociones se construyen y trasforman (cfr. Duveen y Lloyd 2003). 
Los procesos de representación social se configuran mediante la complementación de dos funciones, a saber: la objetivación y el anclaje (ibíd.). La objetivación es la trasformación o concreción de lo que eran meras ideas abstractas en algo existente; en tanto el anclaje es precisamente el hecho por el que algo que no es propio, sino remoto, se asimila dentro de las categorías conocidas de la cognición cotidiana, influyendo en la manera de actuar.

La objetivación es la realización de un traslado: de lo ajeno o incluso inexistente en algo existente y cercano; en algo que ahora es para nosotros (una selección de elementos teóricos que se descontextualizan para naturalizarse, según Jodelet 1986). En este momento se hace preciso vincular el objeto, hecho, proceso o fenómeno que se está objetivando con los valores e ideas que han marcado la pauta del existir previamente. Como se trata de un proceso de índole social, tal realización requiere explicaciones y justificaciones. En esta lógica, este proceso no es homogéneo, sino diferenciado según las diversas posiciones de los actores.

El anclaje se verifica en la manera como lo objetivado ahora orienta y justifica la actuación, en la toma de decisiones y en el hacer. Son nuevos recursos para la acción; obviamente actuaciones concordes con las imágenes nuevas, que no están descargadas de ideología según la específica fuente de la que provienen.

Este proceso de re-presentar - hacer presente a algo o a alguien — confiere carácter natural y ontológico al objeto de la representación, en el sentido que asigna la misma significación tanto al contenido de lo representado como al proceso mismo de construcción de la representación (cfr. Jodelet 2000). He aquí uno de los aspectos que no deben pasarse de lado, pues al ontologizar ubicamos a lo representado en un terreno que dificulta reconocer la carga ideológica que contiene y le caracteriza.

En esta comprensión, vale recuperar la recomendación de Goldmann (1976) en cuanto a la necesidad de identificar la estructura significante; es decir, la importancia de no perder de vista al grupo social del que emana la representación y de la funcionalidad del contenido de 
la misma. Este hecho fundamental para entender y analizar las representaciones sociales comúnmente es dejado de lado.

Profundizando en la funcionalidad de las representaciones sociales, según Palacios (2009) se trata de sistemas de clasificación que facilitan el entendimiento de motivos e intenciones que conllevan las acciones de las personas y que forman opiniones. Tajfel (1984), por su parte, en sus estudios sobre cognición y la interacción entre grupos socioculturales, dialéctica y complementariamente remarca que orientan la comprensión misma, es decir, encausan hacia una interpretación específica de los hechos, procesos y fenómenos sociales $\mathrm{y}$, por tanto, la manera de relacionarse con los mismos. Al ofrecer un marco particular de permisividad y justificación de las acciones, se genera diferenciación entre los grupos sociales, lo que queda claro en este estudio, pues difícilmente la misma representación que tienen los chuj sobre la educación escolar será compartida por otros grupos sociales en otra ubicación en el entramado social.

Estas mismas ideas son profundizadas y complementadas con los planteamientos de Abric (2001) en cuanto a que las representaciones son apropiadas por los individuos y los grupos. Son lecturas particulares del contexto, para poder actuar en él, de acuerdo con los códigos predominantes y bajo la influencia de los elementos del discurso (cfr. Foucault 1970) como poder e imposición ideológica; hecho señalado con contundencia por Grize, Vergès y Silem (1987), al remarcar que las representaciones están inextricablemente vinculadas a la naturaleza de las condiciones de producción del discurso.

Así, el sentido social de la realidad que se comparte es elaborado con preponderancia de las reglas del contexto, que le impone condicionantes e implicaciones; de manera que tal sentido está atravesado por el contexto — que a la vez de ser determinante es determinado por relaciones de clase- - Doise, Clémence y Lorenzi-Cioldi (2005) también lo plantean al llamar la atención de los efectos del contexto ideológico sobre las representaciones y el lugar que ocupa en el sistema social el individuo o el grupo. 
Son tres las dimensiones a considerar en el estudio de las representaciones sociales: la información, el campo mismo de la representación social, y la actitud como orientación del comportamiento (Mora 2002). El primer punto es el de la información —piénsese en el control y manejo que se tiene de la misma-. La información que recibimos no cae en el vacío sino que se relaciona con la organización del conocimiento que tenemos previamente.

El campo de la representación remite a través de una o varias imágenes lingüísticas al contenido concreto y limitado del conjunto articulado y jerarquizado de proposiciones expresadas. Es una forma de apropiación de la información que permite pasar de lo escuchado a lo que se expresa en contextos específicos y ante determinados interlocutores o auditorios, como forma particular de interacción. Puede ser visto también como la expresión políticamente correcta o como la categoría o categorías básicas sobre las que se elabora una narrativa o, en su caso, una respuesta a cuestionamientos emergentes - que conllevan ya una forma «acertada» de responder- (cfr. Moscovici 1979).

Después de haber hecho inteligible la realidad en el campo de representación, realidad por demás cambiante y con controles externos y extraños, la actitud corresponde a una forma de integración; es ésta la que corrobora una actuación acorde con el campo de la representación y es, a su vez, un mecanismo para no quedar segregados. Pero en este caso no debe pasar desapercibido que es, de acuerdo con Foucault (1976), el «panóptico» el principal interesado en que las personas no se comporten de maneras «indeseadas»; es la maquinaria de vigilancia que adquirimos, nos hacemos parte de ella y a ella la hacemos parte de nosotros de manera que la reproducimos. Así que en este caso se trata de lo que hacemos ante los ojos interesados en sancionar nuestro comportamiento.

En este momento debemos detenernos un instante en la manera como se conforman las representaciones sociales, que deben considerarse paralelas y complementarias a las dimensiones expresadas. Moscovici (1979) plantea tres condiciones de emergencia: 1) la dispersión de la información, que nos hace reconocer que ésta sin ser completa, sino desorganizada y limitada pero superabundante, es expuesta machaconamente y con el grado 
de suficiencia apenas como para garantizar que sea utilizada en argumentos o respuestas a los cuestionamientos; 2) la focalización, que nos hace reconocer las ubicaciones diferenciadas de frente a los discursos y a la información, de manera que la implicación de los sujetos en la representación y en lo representado es diferente, verificándose, desde luego, procesos de exclusión; y 3) la presión social hacia la inferencia, es decir, las exigencias sociales para no quedarse callados o al margen, sino a expresar las opiniones o posicionamientos de frente a las cuestiones consideradas de interés público.

Después de dejar establecido el marco de comprensión de las representaciones sociales, nos queda sólo ofrecer un par de aspectos relacionados con el tema de la educación. Esto nos ayudará a comprender el ámbito específico de la construcción social que analizamos y a entender el marco en que se realiza la educación escolar en las comunidades del pueblo chuj en Chiapas.

La reflexión que hacemos al respecto nos conduce a poner atención en el tema de la interculturalidad, resaltando las formas particulares de construir la realidad por parte de los pueblos, no solo desde sus peculiaridades culturales, sino también desde su específica posición en el contexto, que es, por supuesto, una posición relacional. Así es que debemos reconocer y argumentar las diferencias, como lo sugiere Maldonado (2004) para el trabajo educativo, y trascender las tendencias homogeneizantes del Estado que las oculta o minimiza.

En el caso de la educación escolar que se imparte entre los pueblos indígenas, la exigencia hacia la perspectiva intercultural resulta contundente; en concreto y como sugiere López (2000: 7), enfatizar la dimensión cultural, apuntalar un aprendizaje que responda a las necesidades básicas y que sea significativo, así como social y culturalmente situado:

La dimensión intercultural de la educación está también referida tanto a la relación curricular que se establece entre los saberes, conocimientos y valores propios o apropiados por las sociedades indígenas y aquellos desconocidos y ajenos, cuanto a la búsqueda de un 
diálogo y de una complementariedad permanentes entre la cultura tradicional y aquella de corte occidental, en aras de la satisfacción de las necesidades de la población indígena y de mejores condiciones de vida.

Saldívar y Rivera (2006), por su parte, en su análisis sobre la relación entre pobreza y educación, dentro del estudio de las representaciones sociales de la pobreza en Chiapas, analizaron que aspectos socioculturales como el idioma y la discriminación, entre más, resultaban factores determinantes de accesibilidad a la escuela y, además, que junto con el ser indígena y la importancia de leer y escribir, resultaban también subcategorías asociadas a la pobreza y factores para dejar de serlo. Estos autores concluían invitando a «profundizar en documentar, de qué manera y con qué magnitud se da este fenómeno de desvaloración de lo propio en el contexto de los proceso educativos y sus repercusiones directas en los proceso de migración y negación sociocultural, asociados a la escuela como reproductora de las condiciones de inequidad» (ibíd.). Confiamos que el presente estudio constituya un aporte en este sentido.

\section{METODOLOGÍA}

El presente texto tiene como base un trabajo de campo realizado en ocho colonias del estado de Chiapas en que las personas del pueblo chuj son mayoría. Son comunidades con población entre 104 personas la que menos y 212 la que más. Nuestro trabajo comenzó con la solicitud de aceptación en la asamblea de cada comunidad entre los meses de septiembre y octubre de 2008, concluyendo la fase de trabajo de campo para este estudio en el mes de diciembre de 2009. La intención a mediano plazo del proyecto es elaborar, con base en la comprensión de la relación entre escuela y comunidad, un planteamiento de educación basado en el conocimiento cultural del pueblo chuj. Lo que ahora se expone es sólo una parte preliminar que se confrontará con otros datos y análisis que nos permitirán elaborar nuestro planteamiento. 
Una vez aceptados en estas ocho localidades de los municipios de La Trinitaria, La Independencia y Las Margaritas, procedimos a realizar entrevistas semiestandarizadas a un porcentaje entre $40 \%$ y $80 \%$ de los hogares de cada una de las comunidades, conversando con al menos una persona adulta del hogar — en ocasiones con dos o más- y entrevistas en profundidad con aquellas personas que se mostraron dispuestas; de igual manera tuvimos encuentros y diálogos con los profesores de las escuelas primarias y los alumnos de las mismas. El análisis que presentamos en el presente texto está basado principalmente en las respuestas a las entrevistas semiestandarizadas con preguntas abiertas orientadas a los temas de la educación, la escuela y los conocimientos culturales. Las entrevistas fueron realizadas siguiendo un patrón azaroso, quedando partes proporcionales prácticamente por mitad: las entrevistas en chuj alcanzaron 56\% y el resto se realizaron en castellano. De las entrevistas en chuj, una mitad se hicieron con traducción simultánea y las otras con traducción posterior. Unas y otras expresan las mismas representaciones sobre los temas de la educación y la escuela, independientemente del sexo, de la edad y de la comunidad.

En la lógica de lograr un análisis que distinga tanto las dimensiones de la representación como sus funciones, siguiendo el marco teórico metodológico expuesto, se han identificado las categorías básicas expresadas en las respuestas a nuestras preguntas, confrontando unas con otras para detectar aquellas que configuran el núcleo central de la representación al que se anclan los referentes empíricos y aquellas otras de índole periférico. Las preguntas que analizamos versaron sobre la educación y la escuela, tratando de distinguir aquellos aspectos que le confieren tanto una connotación positiva como una negativa a ambas y también sobre la relación entre la comunidad y la escuela.

En todas las comunidades, se trata de escuelas primarias, tres de ellas unidocentes y las otras con dos profesores - multigrado- por escuela. Unas pertenecen a la Secretaría de Educación Federalizada, SEF, otras al Programa Educativo Comunitario Indígena, PECI, y otras están bajo la responsabilidad del Consejo Nacional de Fomento Educativo, CONAFE. En ninguna de las comunidades hay docentes del pueblo chuj y ningún profesor habla este idioma. 
A las ocho comunidades de estudio se accede primeramente por camino asfaltado y finalmente por camino de terracería; las dos más cercanas están a una distancia de una hora de la ciudad de Comitán y las dos más alejadas están a tres horas. Todas ellas fueron fundadas por personas que habiendo nacido en Guatemala llegaron a México en condición de refugiados. Durante el periodo del refugio que se extendió durante quince años, entre 1981 y 1996, cuando se logró la firma de los Acuerdos de Paz en Guatemala, la educación que se impartía en los campamentos estaba a cargo de miembros capacitados de la misma comunidad refugiada; se realizaba en el propio idioma, ponía de relieve aspectos culturales propios y se impartía, por ejemplo, tanto la historia de México como la de Guatemala, e inclusive se cantaban los dos himnos.

Cuando concluyó este periodo y la mayoría retornó al vecino país, quienes quedaron tuvieron que gestionar terrenos nuevos - logrando por lo general espacios muy reducidos - y todo tipo de servicios oficiales, incluyendo las escuelas. La educación que se ha impartido a partir de esa fecha dio un giro total y los aspectos culturales y de origen de las comunidades quedaron completamente relegados. Cuatro de las escuelas son construcciones de cemento y las otras cuatro son de madera con techo de lámina. A excepción de una de las colonias que cuenta con un espacio enmallado, exclusivo de la escuela, las demás no tienen espacio propio y propicio para la realización de actividades escolares. Ninguna tiene plaza cívica o cancha de juegos, y en la larga época de lluvias los juegos y actividades fuera del aula se hacen en condiciones poco favorables.

Tanto las comunidades como los docentes nos expresaron la algidez del tema que abordamos y con temor, en ambos sentidos, nos expresaron sus ideas y opiniones. Los profesores con el temor de ser evaluados negativamente y evidenciados en algunas de sus prácticas, y las comunidades con el temor de que al hacer un juicio crítico la respuestas de las autoridades educativas fueran a sancionarles quitándoles los docentes o tensando la relación con los profesores, con repercusiones negativas hacia los hijos dentro del aula o en las notas. En este sentido, nos hemos comprometido a reservarnos la identidad, tanto de las 
personas como de los nombres de las comunidades en particular. De cualquier manera, asumimos la responsabilidad ética de hacer este análisis y corroboramos que en términos generales la situación que se vive en estas comunidades es semejante entre sí y es la misma que se vive en el resto de comunidades chujes de la región.

\section{ANÁLISIS DE DATOS}

\section{LA INFORMACIÓN}

Expondremos en un primer momento las tres dimensiones de las representaciones sociales en torno a la educación escolar. Comenzamos con la dimensión de la información que, recordando, es aquello que escuchamos mediante discursos, opiniones, medios de comunicación, entre más, y que versa sobre el aspecto en cuestión; su objetivo es ir generando opinión y, sobre todo, comportamientos acordes. En este caso, siendo el tema la educación escolar, la principal fuente informativa proviene de los profesores y de sus supervisores, pero también de los medios y de los profesionistas que por uno u otro motivo tienen vínculo con la comunidad —entre los cuales de alguna manera estamos-, además de la que los mismos chujes circulan entre sí según experiencias familiares diversas. La información más remota que tienen proviene de Guatemala, de la época de niñez de los adultos. Esta información es compartida por las personas mayores de treinta años y expresa una serie de elementos que reflejan exclusión y crítica:

\footnotetext{
Antes, en Guatemala, por ser indígenas nuestros papás nos escondían de los maestros. Son inteligentes nuestros padres, y para que el maestro no hable se le regala una gallina a cambio de que no diga nada de que vayamos a la escuela. Por eso la mayor parte de la gente, como de mi edad ya adultos, somos mudos, ${ }^{2}$ y como mujeres únicamente nos dedicamos en el quehacer de la cocina. Eso era una gran discriminación hacia nosotras por ser mujeres, pero como es orden de nuestro papá debemos obedecer. Los que se van a la escuela es que no tienen trabajo.
}

Nosotros como papás somos dejados pero hoy en día el niño no debe quedar dejado, debe estudiar para que sea vivo y para lograr una vida mejor; en cambio nosotros estamos jodidos, por culpa de un gobierno guatemalteco que no le interesa la educación de su gente. 
Estas expresiones contienen una serie de formulaciones dicotómicas cargadas de significado: indígenas y no indígenas, antes y ahora, Guatemala y México, padres e hijos, mujeres y hombres, ser dejado y ser vivo, inteligente y «mudo». Estas formulaciones señalan cierto contexto de relación con la escuela y con los maestros, en las que se formulan ideas como: «a la escuela van los que no tienen trabajo», «la escuela no es para los indígenas» o «la escuela no es para las mujeres». Adicionalmente se formulan algunas denuncias como la discriminación por ser mujeres y la de estar «jodidos por culpa de un gobierno guatemalteco que no le interesa la educación de su gente». Como iremos viendo, esta información está presente en las representaciones sociales de la educación escolar, lo que significa que ella se sigue reproduciendo y reforzando y se suma a la construcción de una realidad cargada de estos elementos.

La información proveniente del propio sector educativo se reitera una y otra vez en las reuniones de profesores con padres de familia, en las presentaciones de los nuevos docentes, en reuniones con autoridades educativas regionales, en las ceremonias y festividades escolares, en el día a día dentro del aula. Esta información contiene imágenes claras de:

1) distinción cultural, que ubica a los chuj en un estatus menor de frente a una cultura nacional castellana — «necesitan el castellano para que avancen»-. A esta imagen contribuyen también la prohibición a que se hable chuj en las escuelas e incluso en las reuniones con los padres de familia y la asociación que se hace de lo chuj con Guatemala, sugiriendo la incompatibilidad entre lo chuj y lo mexicano — «acá es México y en México se habla el español»); el mensaje es que no se puede ser chuj y mexicano al mismo tiempo (cfr. Limón 2008).

2) Supremacía institucional de frente a la comunidad — «nos exigen comprar ropa sin consultar a nosotros. ¡Tenemos la capacidad!, ¿o no? Esto, para mí, es que a los maestros les falta educación»- En esta tesitura, la comunidad tiene un lugar subordinado y es la que debe ayudar a los maestros en la educación de los niños, y si la comunidad no acata las disposiciones institucionales se le sanciona, inclusive retirando a los docentes. 
3) Descalificación al analfabetismo. Un muy alto porcentaje de los adultos es analfabeto, sin embargo, ante los alumnos, reiteradamente se le asocia con la ignorancia. En esta comprensión, la sabiduría de los mayores, aprendida a lo largo de la vida y a través de las estrategias de aprendizaje del conocimiento cultural, queda totalmente entredicha.

4) El objetivo de la educación en los niveles básicos es que los egresados se incorporen y continúen sus estudios en los niveles más avanzados. Esta es una de las consignas más remarcadas y que establece un criterio de satisfacción entre los docentes — «Nuestro objetivo principal es que los alumnos aprendan y pasen a la secundaria, que sigan en los siguientes niveles de estudio».

Estos cuatro aspectos, como se remarcará, están presentes en el campo representacional de la educación escolar: devaluación y desprecio por lo chuj —al lado de la mexicanización obligada - una nula relación entre la escuela y la comunidad en términos de proyecto, la exaltación de la lectoescritura en español y la intención, sin más, de que los alumnos se incorporen al nivel inmediato superior al que se encuentran.

La otra fuente de información es la que los profesionistas llevan consigo; se trata de personas que efectivamente transitaron por los diferentes niveles educativos para llegar a ser licenciados, ingenieros o médicos. En ocasiones estas personas son explícitas a favor de que los niños vayan a la escuela «para que se superen», pero fundamentalmente se expresan por medio de su forma de trato, en sus gestos y comportamientos y, sobre todo, en sus intenciones e intereses en la relación con la comunidad, que frecuentemente es utilitaria o de promotores-ejecutores de planes y programas, ubicando a las personas de la comunidad como simples receptoras y con la adición de proferir calificativos lacerantes hacia ellas como de necias, ignorantes y conformistas. 


\section{EL CAMPO REPRESENTACIONAL}

La siguiente dimensión es el campo representacional. Debemos comenzar por recordar que dicho campo remite por medio de imágenes lingüísticas al contenido concreto y limitado de las proposiciones expresadas, las cuales son un conjunto con articulaciones y jerarquías.

El campo representacional de los chuj mexicanos en relación con la educación escolar está acotado básicamente a aprender a hablar, leer y escribir en español. Esta es la respuesta unánime: «La educación es para aprender a leer y escribir», «obligarnos a aprender el castilla», «en la escuela se aprende a escribir y leer», «una buena educación es aprender a leer y escribir y depende del maestro que está enseñando», «tener una educación es muy importante; al no saber leer y escribir somos como un niño de cuatro años: vivimos, nos movemos pero no sabemos pensar», «lo bueno es conocer y aprender otra lengua, saber escribir y leer».

La experiencia de los chuj en relación con la educación escolar les lleva a circunscribir el campo representacional a esta imagen básica o principal, que expresa un contenido concretísimo y muy limitado. Una niña, de once años, de una escuela primaria nos lo confirmó: «Pues yo no he aprendido nada de historia, ciencias naturales, ni de geografía, y eso deberíamos aprenderlo en la escuela».

Ahora bien, este campo se complementa, reforzándose con el conjunto completo de las proposiciones expresadas. Estas proposiciones también son manifestadas a través de otras imágenes igual de contundentes, que quedarán más claras en el momento que reflexionemos en torno a la objetivación.

Como ya quedó de manifiesto en las expresiones anteriores, este aprendizaje «depende del maestro que está enseñando»y, adicionalmente, que «al no saber leer y escribir somos como un niño de cuatro años: vivimos, nos movemos pero no sabemos pensar». Así que el aprendizaje de la lectoescritura en español no es un asunto aislado, sino que está en 
conjunto con diversos aspectos que le dan marco de comprensión dentro del campo representacional.

El núcleo central de la representación se confirma con otras nociones periféricas en las que se consolida; en este caso las encontramos al inquirir en torno a la noción de «buena escuela», la cual ofrece imágenes cognitivas que están dirigidas hacia lo que se expresa como una buena educación. La buena escuela es aquella en que los niños crecen en conocimiento, que es una categoría que remite a los valores culturales y tiene como referente la vida misma, la naturaleza y el vínculo religioso con lo existente (cfr. Limón 2009). En la buena escuela los niños son «formados como personas de respeto», «aprenden a ver y conocer algunas cosas», «ahí aprende uno a tener conocimiento y se va mejorando su persona». Complementariamente, esa escuela «cuenta con materiales» y en ella el maestro «está bien preparado o formado con mucho conocimiento», «tiene capacidad»y «sabe la cultura de nuestro pueblo, para poder trabajar con los niños y que tengan buena comunicación». Así que buenos maestros, capacitados, con material y conocedores de la cultura del pueblo con que trabajan favorecerá que los niños sean personas de respeto y crezcan en capacidad de comunicación. Tal es la caracterización de la buena escuela.

Como Abric (2001) lo plantea, las representaciones sociales se reconstruyen en el sistema cognitivo previo, integrándose en su sistema de valores, que dependen de la historia y del contexto mismo. Las representaciones, por consiguiente, requieren del propio y consolidado sistema de referencias, pues éste pauta la posición que se toma ante los hechos. Es de esta manera como emergen las nociones de respeto, conocimiento y comunicación, tres de las categorías fundamentales en el modo de vida chuj (cfr. Limón 2009).

Así, la buena escuela en la expresión y el deseo de las y los entrevistados contiene ya elementos que corresponden a la cultura chuj; sin embargo, encontramos reiteradamente la respuesta de que esa buena escuela, en las comunidades chujes no existe: «no hay buena escuela», expresan clara y contundentemente, lo que pone de manifiesto la tensión entre el campo representacional y la actitud como orientación de comportamiento y, sobre todo, 
pone de manifiesto el alcance del campo representacional, distante de lo que se tiene como anhelo fundamentado en la cultura propia.

Recordemos que el campo representacional puede también ser entendido en aquellas expresiones que pueden ser consideradas correctas o adecuadas, ante determinados actores o agentes del sistema y que permiten mantener una cierta interacción. De esta manera el argumento para sostener la imagen central o, dialécticamente, la imagen hacia la que está dirigido el argumento es hacia la vida futura de los niños, como punto de contacto con el discurso escolar, un futuro sin los sufrimientos de la actual generación adulta:

Sí, aporta. Al tener una educación uno mismo pude obtener un trabajo y permite buscar la vida, la comida; además: ser inteligente.

Esta vida no la podemos dejar a los niños; aunque nosotros como papás somos dejados, pero hoy en día el niño no debe quedar dejado, debe estudiar para que sea vivo y que haga una vida mejor.

Las expresiones reflejan aquellas imágenes en las que el sí mismo está devaluado y es la escuela la que puede favorecer la transición hacia un estado diferente, hacia un estado de bienestar. «Estoy contento por sus esfuerzos de mis hijos que hacen por conocer algo de su vida, porque nosotros estamos ciegos y tenemos una venda en el ojo». Así es como se justifica el esfuerzo para que los hijos aprendan a leer y escribir, donde la vida termina poniéndose en posición subalterna o de dependencia respecto de la educación escolar; donde el futuro de la vida se consigue mediante el esfuerzo individual y a través de mantenerse en la educación escolar.

\section{ACTITUD COMO ORIENTACIÓN DEL COMPORTAMIENTO}

La última dimensión de las representaciones sociales es ésta, en la que el actuar corrobora que se tiene la disposición «correcta». No basta con que se diga que la educación escolar determinará la vida futura de las jóvenes generaciones, sino que los actores interesados en esta posición están demandando que se actúe de conformidad con lo dicho. Esto es expresado nítidamente también por las y los entrevistados. Aquellos sujetos estarán 
satisfechos al escuchar y verificar que los niños van a la escuela, independientemente de que ésta funcione como funcione - como lo iremos viendo-. En esta lógica es como se entienden y hasta se aplauden aseveraciones como éstas: «Yo en mi caso, con mi esposo, exigimos que los niños terminen sus estudios, porque cuando los niños quedan analfabetos es culpa de los padres de familia». «Así es la mayor parte de la gente: no le interesa el estudio de sus hijos, no los mandan a clases, los ocupan en algún trabajo». «Para que se logre salir adelante, lo primero es que el papá debe ser exigente y no tanto los maestros».

La actitud remite a vínculos de responsabilidades concordantes tendentes al mismo objetivo, sancionado en el campo representacional: «Cuando mandamos nuestros hijos a la escuela tenemos un objetivo: que se le facilite su vida de ellos». Sin embargo, definitivamente no queda esta actitud de responsabilidad en los padres de familia. Debemos exigir sus tareas, quiere decir que estamos interesados en su estudio y si no hay tarea quiere decir que los maestros no tienen un interés de trabajar con los niños. Eso a mí me molesta. Como el día de hoy, yo lo voy a mantener al maestro [le voy a dar de comer] y si no aprenden mis hijos, pues ahí podemos entender que solamente los mantengo sin que ellos enseñen algo a nuestros hijos.

De tal forma que la actitud de los padres de familia debe encontrar consonancia en lo que perciben de los maestros: «Los maestros actuales son exigentes, es para que lleguen bien preparados en la secundaria».

Mas, como se va apreciando, las actitudes no son del todo coherentes u homogéneas, no obstante las respuestas sí hayan sido homogéneas y contundentes en el sentido de que la educación escolar es para que los niños aprendan a leer y escribir, núcleo central de la representación. Inconsistencias las hay también en las diferencias declaradas entre las expresiones respecto de la buena escuela - la que no hay en sus comunidades - y las opiniones que responden al de qué depende que haya esa buena escuela. 
Para entenderlo mejor, primeramente vale expresar aquellas ideas referentes a la mala escuela. Ésta, en el decir chuj, es aquella donde «los maestros no trabajan bien», «los maestros no están entregados al trabajo y ellos toman sus decisiones cuando quieran»; en la que «los maestros regresan a su casa muy temprano» $\mathrm{y}$ «no les interesa la enseñanza de los niños». Esta mala escuela «es de madera», «sigue programa de gobierno», y en la cual «las madres de familia nunca tenemos reunión con los maestros como mujeres». Es una escuela que «la verdad no aporta mucho porque hay una mala enseñanza». En su representación es la clara imagen de la escuela vigente en sus comunidades.

Cuestionamos a una joven de secundaria respecto de la escuela primaria de su comunidad, de donde había egresado un par de años atrás: ¿Qué le cambiarías? Su respuesta fue elocuente en términos de la actitud de los maestros, pues refuerza claramente el núcleo de la representación: «La forma de enseñar, porque a lo que se dedican los maestros es sólo leer y escribir, pero es importante que enseñen sobre lo que nos rodea...».

Más allá de estas actitudes y disposiciones de los maestros y de las condiciones materiales de las escuelas que son muy precarias, se presentan los tres últimos aspectos referidos como muy relevantes: el programa de gobierno, el nulo involucramiento de las mujeres que se extiende en general a la comunidad y la mala enseñanza. Debemos detenernos un poco en ello.

En la mala escuela se aplica el programa de gobierno, es decir, que éste es parte de la mala educación. Un anciano, de 86 años, expresó una crítica feroz, la cual exhibe con contundencia la lógica con que se elabora un programa de gobierno y sus consecuencias:

De mi parte algo que me encabrona con la juventud es por qué los estudiantes leen la historia de un gobierno corrupto, ladrón, asesino, ¿sólo porque tuvo un poder para gobernar al país? ¿Y por qué no los estudiantes leen o que se fijen o pregunten la experiencia de un abuelo o viejito? Y como somos tan pendejo ¡qué va a saber ese viejito, analfabeto!, así dicen ellos. Pero en verdad eso no se reconoce y en verdad allí, en ellos, está la esencia de la vida, todo lo bueno y sano de nuestra 
historia. En cambio de estar leyendo de esos personajes falsos que confunden la mentalidad de nuestros hijos actuales.

¿Qué autoridad moral tiene un gobierno para determinar el contenido ideológico de la formación impuesta a todos los educandos? ¿Cómo va a poder justificarse un programa que tiene concreciones indeseables y nefastas? El programa de gobierno además tiene concreciones en las actitudes de los maestros. Un padre de familia ahora elabora la siguiente crítica:

En el salón tienen prohibido «hablar como indios», «están en México, ya no están en su país». Los niños más chiquitos como sólo hablan chuj son castigados, porque el maestro les hace preguntas y ellos no contestan, hay los ponen en los rincones o los sacan del salón, los mandan a que vayan a trabajar en la milpa...

Y veamos que éstas no son falsas imágenes o insolencias de los padres de familia, pues finalmente un maestro nos constata el ámbito de sus propias actitudes en la lógica de los programas de gobierno ... nosotros los maestros no podemos ir en contra del gobierno, porque él ya tiene un plan y si nos preguntan, nosotros no tenemos un plan de trabajo con el que podamos justificar por qué estamos trabajando de acuerdo a la cultura de los niños ... Lo que se exige es que ellos aprendan español...

En cuanto a la no participación no solo de las mujeres, sino en general de toda la comunidad, ésta es la parte que pone de manifiesto el punto de mayor distancia entre el campo representacional y la actitud y da respuesta a aquella pregunta ¿de qué depende que haya una buena escuela? Las respuestas que recibimos fueron nuevamente uniformes: «De nosotros», «de los padres de familia», «de darle importancia», «que haya interés»; de que «haya una reunión para discutir las fallas... un espacio para mejorar la escuela». Estas respuestas señalan una autocrítica en la que se asume la responsabilidad de lograr una buena escuela, con una buena educación; sin embargo, lo que ya no es generalizado es la actitud constructiva - aunque ésta sí comienza a verificarse en algunas comunidades y de parte de algunos padres de familia, quienes encuentran diversas reacciones en los profesores, algunas favorables y otras de indisposición. 
En cuanto al tercer aspecto al que remitíamos en la crítica de la mala escuela, aparece la categoría: enseñanza, que nos pone en relación de complementariedad y de comprensión con otra categoría: orientación. Este par: enseñanza-orientación, es el par categorial que se vincula al conocimiento cultural y desde el cual es factible construir una teoría, es decir, elaborar una teoría fundamentada desde la cultura del pueblo chuj referente a la enseñanza, — sin decir «educación» que siga reproduciendo el discurso- ${ }^{3}$. Enseñanza-orientación son el contrapeso a la representación sobre la educación, que ubica a esta última en manos de los profesores y del sistema educativo; aquel par, en cambio, ofrece la clave de acceso al ámbito formativo en el que la comunidad es la responsable y donde la base es la sabiduría de los abuelos y las abuelas, la relación con la naturaleza y con los espacios sagrados y tiene en el horizonte la vida, vida cultural, vida comunitaria, vida del pueblo - ya no la vida asignada en el campo representacional, como vida del individuo que adquiere las habilidades para ya no ser como los papás, para trascender la vida de su comunidad en el ámbito rural y proyectarse en una vida de competencia laboral-. Veamos algunas expresiones que hablan de esta tensión:

- La enseñanza de nuestros abuelos es nuestra lengua materna que disfrutamos como adultos o niños; y además no nos avergonzamos de hablar porque es la cultura de ellos que nos dejaron. Antes los niños respetan a los ancianos con el acto de ja'ojk'ab' [que es ofrecer la cabeza para un saludo y una bendición] y en nuestra vida actual ya no, los niños que van a la escuela se burlan de los abuelos más viejos.

- En la época del refugio los que fuimos promotores de educación enseñábamos las enseñanzas rituales, como el 8 de febrero y del oye' k'u [fiestas rituales y tradicionales en el calendario maya chuj].

- Ella se formó con los maestros ex refugiados que hoy en día son naturalizados con buenas experiencias. Aunque ellos no estudiaron, pero fueron capacitados en la materia de educación y lo hacían muy bien sus enseñanzas. ¡Cómo nos daba gusto de cómo trabajaban!

- ... y si se dedica para hacer las tareas [escolares] se descuida en estas enseñanzas de la casa y se desenlaza como robalón, por no ser orientado.

- La mala educación es cuando los maestros no trabajan bien ... no les interesa la enseñanza de los niños. Ahí se ve que no tienen su responsabilidad.

- Están enseñando unos maestros no capacitados, ni saben cómo enseñar, por eso los niños no aprenden ... Los que saben leer ya se sienten los únicos conocedores, tienen su carácter del 
machismo. Por esa razón los que tienen un poquito de estudio ya se sienten como autoridad, por lo que conocen algo ... Vuelvo a repetir: el estudio lo perjudicó y sigue confundiendo a que ya no se respete esta cultura.

Estas frases son de gran contundencia y evidencian la distancia existente entre el sistema educativo, con su educación escolar, y las enseñanzas requeridas para vivir la vida comunitariamente y en sentido cultural. ¡Cuán distantes quedan entre sí las intenciones de la lectoescritura en español y el respeto de los niños a los ancianos, como principal manifestación de buena educación en sentido cultural!; entendido el respeto como el principio de la ética chuj y el fundamento de la vida comunitaria (cfr. Limón 2009b). Son distantes también el requerimiento del idioma chuj, las festividades rituales, el tiempo en que los profesores eran personas del mismo pueblo chuj, el orden en la casa, etcétera. Por lo contrario y consecuencia de la educación hay el irrespeto, la irresponsabilidad, la dificultad de ser orientado y la eventualidad de «desenlazarse como robalón», la confusión en los niños, la negación de su enseñanza, el machismo, entre más.

El señalamiento de esta crítica no lo podíamos soslayar, pues es muy importante en este momento, ya que nos facilitará la comprensión de los momentos de la objetivación y el anclaje, que pueden ser comprendidos solamente si se considera el marco cultural previo.

\section{OBJETIVACIÓN}

La objetivación es el vínculo que se hace con lo que se tenía previamente como propio. Ahora, entonces, debemos poner de manifiesto aquellos aspectos que hacen el vínculo y que en otro momento permiten el anclaje, es decir, que son los elementos de conocimiento que dan marco y pauta a su aceptación y reproducción.

Entre los chuj, la representación social sobre la educación escolar encuentra su naturalización a través de la remisión a algunos valores e ideas que previamente han marcado la pauta del existir. Ya expusimos aquella frase contundente de que «al tener una educación uno mismo pude obtener un trabajo y permite buscar la vida, la comida». ¿Qué 
mayor valor que buscar las condiciones materiales de existencia! Esta objetivación ciertamente es más expresada por quienes tienen mayores restricciones en su alimentación.

De igual manera emergen cuestiones básicas relacionadas con este mismo criterio material, entre quienes establecen relaciones comerciales en condiciones de desventaja: «El estudio es bueno, para que aprendan los niños, porque cuando compramos o vendemos nuestro producto ellos harán la cuenta». La misma experiencia de abusos y robos en las transacciones de compra-venta lleva a justificar esta educación. Pero las relaciones en torno a las condiciones materiales de existencia no son las únicas que las justifican. Entre las personas mayores, que vivieron experiencias de desencuentros con el gobierno guatemalteco, destacan la relación que se tiene con las autoridades; así, por ejemplo, en los casos de la recepción de «algún oficio que viene por autoridades, [entonces] ellos [los hijos que saben leer y escribir] deben saber qué dice el papel». De este modo podrán tener condiciones de analizar y responder sin ser sujetos a falsaciones, utilización o engaño.

Otro de los aspectos que fueron mencionados, particularmente por quienes tuvieron algún cargo en la época de refugio que les implicaba relacionarse con personas con muy diversas funciones, es su intención de que sus hijos, mediante el uso del castellano, logren establecer amistades en las ciudades, con gente que está ubicada en espacios a los cuales eventualmente podrán tener necesidad de acudir. «La escuela nos ayuda a comprender una comunicación y tener una amistad». Esta noción de «tener una amistad» remite a aquella relación que se tienen con gente castellana de las ciudades: «Tengo una mi amistad» es la forma de afirmar que se cuenta con una relación que eventualmente le apoyará en algo, alguien conocido con quien siente que puede establecer tratos o acuerdos y no ser uno más ante un desconocido que le haga sentir desprecio, abuso e injusticia.

«Una buena escuela es para que aprendan a ver o conocer algunas cosas. Ya con eso ellos responden a un cargo». En la buena educación «los niños van a estudiar en la escuela y además les aporta conocimiento, ayudando a su persona a superarse y tomar un cargo en la comunidad». El criterio para ser considerada una buena educación no queda por tanto sólo 
en la superación personal o en los requerimientos cotidianos como individuo o ante personas ajenas, sino que ésta debe ser de utilidad práctica en servicio de la comunidad, mediante la aceptación y ejecución satisfactoria de los «cargos» que ésta asigna a ciertas personas, quienes deber servir obedeciendo y siendo sensibles a las necesidades del colectivo (cfr. Limón 2008b). Así lo remarcan principalmente las familias que ponen su confianza en personas de otras familias a quienes confieren cargos dentro de la comunidad.

«La escuela da estudio, y con esta capacidad se debe responder a un cargo y también es un respeto que se junta a la comunidad porque saben escribir bien». Vemos expresarse con contundencia el vínculo con los valores del pueblo chuj, el servicio, la comunidad, el respeto:

Para que los niños sean mejores y la educación sea buena es un compromiso de los padres de familia, maestros, comité de padres de familia y la comunidad en general. Si nosotros queremos que nuestro pueblo salga en adelante así tendrá un sentido nuestro esfuerzo; y los niños tendrán un futuro si cumplen con todo lo que estamos platicando sobre el respeto y una vida digna.

De esta forma se consolida la validación de la representación social en torno a la educación escolar y se justifica tanto el esfuerzo como el interés porque aprenden los hijos el español: «la educación es buena, ahí se convierten los niños en inteligentes ... entienden ellos el español, ipues es una escuela donde fueron formados como personas de respeto! Aunque es un sufrimiento y un sacrificio el aprender».

\section{ANCLAJE}

Hemos remarcado que el anclaje es el momento en que la representación dirige a la acción. Este anclaje se da en medio de contradicciones, sin embargo no deja de verificarse y de hacerlo con un vínculo muy particular con el conocimiento cultural previo, mismo que en parte le cuestiona y en parte le acoge. Así de dialéctico es este proceso.

El punto nodal es el que ya hemos mencionado: el hijo «debe estudiar para que sea vivo» y los padres «debemos exigir sus tareas, quiere decir que estamos interesados al estudio de 
ellos». Mas estas acciones no se dan en un campo plenamente favorable ni dentro del propio ámbito escolar.

Probablemente en las escuelas grandes habrá un director, en cambio en las comunidades pequeñas un maestro es el mismo director. En esta forma él mismo se cobija de sus fallas engañando al gobierno y a la comunidad, y como víctimas los niños que reciben las consecuencias. Y estos errores no solamente son de los maestros sino también de los padres de familias que no se preocupan de sus hijos; su confianza la tienen en un comité de padres de familia y no se hacen responsables tampoco en su propio deber. ¡Pues que complicación se vive en la comunidad!

Esto que fue expresado por una persona es una constante. En una de las comunidades con quienes realizamos este trabajo, los años previos a nuestra llegada no tuvieron maestro. La reflexión que nos compartieron es que se debió a su reclamo para que los profesores trabajasen bien; lo asumieron como un castigo. Cuando llegamos a esa colonia nos enteramos de cuestiones deleznables por parte de los maestros, con malos tratos a sus alumnas y alumnos. Conversamos y nos expresaron con cierta dificultad y temor el problema. Así concluían: «Ellos vienen aquí a dormir ... a maltratar, a regañar ... insultar como quiera. ¡Ese no! Y por qué se nombran maestros si no saben ellos este ... enseñar nada...». «Ese es el desprecio que yo ... a mí ... no se me va del corazón». No obstante, claro nos dijeron que no dijéramos, que porque tal vez quedarían sin maestros otra vez o sin la validación del ciclo escolar. Así es que ésta se constituye como otra acción de carácter colectivo, dirigida por la representación.

Recordando, para avanzar en el análisis, que una de las intenciones más remarcadas es ir transitando por los distintos niveles escolares, entonces el anclaje también apunta en este sentido: «lo que queremos es que los niños desde aquí se vayan formando para que no los regresen de la secundaria porque tengan baja calificación. Y de mi parte soy exigente, por eso yo tengo un hijo que va con 9.5 de calificación. Esto me hace sentir muy bien».

Orientar la acción no solo se refiere a la acción presente o inmediata, sino también a aquella que se espera tenga concreción en el futuro: 
- El saber leer y escribir es obtener otro conocimiento y además recibirán un beneficio por el esfuerzo que hacen.

- Al tener una educación, uno mismo puede obtener un trabajo.

- Para mí, que estudien los niños más para que obtengan más conocimientos terminando su secundaria y hasta su preparatoria. Hasta llegar a ser mejores.

Un caso muy revelador del anclaje es la respuesta que nos dio una señora con la que conversábamos de si consideraba conveniente que los conocimientos culturales se incluyeran como temas de discusión y aprendizaje en la escuela. Estos conocimientos se han aprendido en la vida cotidiana, en los momentos difíciles o complicados de la vida, donde la cotidianidad misma es cuestionada; en la montaña y en la milpa, a través de los consejos y las conversaciones de los ancianos, de los abuelos y las abuelas. Ella comentó: «Para mí es muy importante, es bueno y es urgente porque los niños aprenderán un nuevo conocimiento, además aprenderán a vivir mejor con todo lo que tienen en su alrededor». Entonces le preguntamos ¿Cómo se debe enseñar esto en la escuela? «Escribiendo en un papel, ya que los niños hoy en día todos saben leer y escribir; que es únicamente darles trabajo a los maestros primero, pero es muy importante». Así es como se verifica la entronización del aprendizaje por medio de la lectoescritura y el papel docente.

Finalmente debemos decir que este anclaje no solo tiene concreción en quienes reproducen la representación sino que además es trasferido a los actores involucrados. Es el caso de nuestra propia presencia en las comunidades abordando este tema. En una conversación que Diego nos tradujo posteriormente, así se manifestó la persona con quien dialogaba:

La escuela tiene una relación con la gente cuando hay una buena comunicación, y si no hay comunicación lo que se espera son los problemas. En este caso los papás se deben organizar para exigir a los maestros, para que haya una buena educación. Y como una opinión, don Fernando debe platicar con los maestros; es como que alguien va a jalar la oreja de los maestros. 


\section{DISCUSIÓN Y REFLEXIONES FINALES}

¿Por qué las representaciones sociales entre los chuj respecto de la educación escolar tienen tan limitado y contradictorio alcance? ¡Este es el tipo de realidad social que construyen! Con ellas elaboran un sentido social que comparten al respecto, con ellas se orientan en el contexto social pero a ellas mismas también tienen que hacer frente. La respuesta a semejante pregunta se encuentra en la constelación de elementos que giran en torno a lo que hoy se vive como educación escolar. Las experiencias remotas de quienes ahora son adultos, lo que les contaron sus padres y que ellas y ellos vivieron en Guatemala, posteriormente en el refugio y actualmente en sus pequeñas colonias, son factores fundamentales para su comprensión.

Su conocimiento cultural, con todas las tensiones, fortalezas y debilidades, haciendo frente al contexto dominante, de enajenación y alienación, contexto que fetichiza a la educación escolar misma; la relación con los profesores y la dinámica escolar, con sus encuentros y desencuentros; las actitudes, dinámicas y discursos de los profesores; lo que ven como concreción en las actitudes de las hijas e hijos que asisten o asistieron a la escuela -independientemente del sistema al que fueran-; lo que perciben que se da en las comunidades de la región y un muy largo etcétera son factores que contribuyen a dicha representación.

Destaca la tensión existente entre lo que se considera como enseñanza, en sentido cultural, que implica el respeto, el saber vivir en el entorno, la proyección de vida en sentido comunitario basada en la memoria, de frente a los resultados tangibles de la educación escolar: una cierta capacidad de lectoescritura muy limitada y una capacidad de hacer cuentas básicas al lado de actitudes de irrespeto y de distanciamiento de los espacios y dinámicas para su enseñanza. No obstante esta tensión, difícilmente se pueden encontrar otras formas de responder a los cuestionamientos que les hicimos en torno a la educación y la escuela, pues es un asunto de interés público - la presión a la indiferencia planteada por Moscovici (1979) — y que se ha consolidado ya como verdadera representación social; 
además, quien lo hiciere de otra forma podría estar cayendo en el desatino, en una respuesta desacertada, políticamente incorrecta ante las demandas del mundo social, de frente al «futuro de sus hijos». Su representación está funcionando, formando las opiniones compartidas y generalizadas, ofreciendo marcos de permisividad y de justificación a las propias incongruencias y de comprensión a las contradicciones.

Mas no es sólo que no pudiesen responder en contrasentido, puesto que de hecho sus respuestas representan lo que la educación escolar es para ellas y ellos como personas, como familias y como pueblo. Esta representación de los chuj evidencia la lógica y el alcance de las representaciones sociales; expresa el sentido social de la realidad que comparten y que elaboran y reelaboran con preponderancia de las reglas del contexto. Y, claro, de no contar con un conocimiento previo de la cultura de este pueblo y de no tener una perspectiva crítica, fácilmente le estaríamos dando un carácter de hecho natural, acotando su perspectiva cultural a tal representación y borrando todo resquicio de memoria y esperanza en ella.

Los niños son obligados a ir a la escuela, aunque ésta sea mala; de igual manera la educación escolar se pone en manos de los maestros, sean éstos buenos o no. Los niños deben ir a la escuela, en ella algún profesor, que va a seguir el programa de gobierno —en sentido educativo-, les va a enseñar a leer y a escribir, a hacer cuentas. Esta educación escolar, se expone a todas luces como algo que les viene de fuera, la ofrece un grupo — social y cultural— que les es ajeno; ellas y ellos sólo resultan «beneficiarios» de este programa de gobierno — como política pública—, uno entre más.

La siguiente expresión, de alguna manera sintetiza lo que hemos venido exponiendo.

La escuela sólo sirve para aprender a leer y escribir. Ya no hay más. Sólo algunos aprenden un poquito lo que es hacer cuentas, sumas y restas. El problema viene cuando quieren entrar a la secundaría y los maestros ya no los aceptan porque no saben nada. ¿De qué sirvió entonces todo ese tiempo en la primaria? ¡Fue tiempo perdido! Así es con la mayoría. Somos analfabetas por culpa de nuestro gobierno. Si continúa esa educación qué futuro van a tener los niños. 
Las representaciones sociales que sobre la educación escolar comparten los chuj, evidencia entonces esta otra tensión complementaria: entre la tendencia hegemónica — verificada en la representación misma - de hacer que los receptores de los programas educativos se sientan «sujetos beneficiarios» de una política y un programa educativo que es propiedad de un grupo social específico que les ofrece de sus propios recursos, como un acto bondadoso dirigido a que se integren competentemente en la sociedad de hoy y de mañana, por un lado, y de frente a esto se encuentra la lógica cultural —en este caso chuj—, que de alguna manera resiste y se le enfrenta, buscando hacer valer ciertos planteamientos que pueden ser entendidos en la lógica de una educación intercultural: que sirva para que «crezcan en capacidad de comunicación», que «integren los dos conocimientos», el del programa oficial y las enseñanzas y orientaciones del conocimiento cultural, en las que «los maestros aprendan nuestro idioma y cultura», entre más.

Qué bonito es cuando no nos avergonzamos de nosotros mismos, cuando les enseñamos a nuestros hijos que hablen en español pero sin dejar el chuj; así cuando una persona quiere hablar con nuestros hijitos va a poder contestar. Si van a la escuela es para que salgan más abusados. Y no para que pierdan nuestra cultura...

Estas expresiones van manifestando cierta conciencia reflexiva que les da recursos para no sucumbir ante su propia representación social de la educación escolar y ante el discurso imperante en la región que sigue intentando «mexicanizar» a los «guatemaltecos», entre ellos a los chuj (cfr. Limón 2008); ambas cuestiones tendentes a vaciarlos de su propio conocimiento cultural y de toda reivindicación cultural. La educación ha sido el principal instrumento de esta pretensión y, ante ello, los chuj están elaborando el reclamo que se dirige hacia que sea desde la misma educación donde se establezcan las bases para la reivindicación cultural, para la reflexión y defensa de sus derechos como pueblo indígena.

Díaz y Alonso (1998: 3) nos remiten a este hecho, en el que se resalta lo positivo de la diferencia cultural y donde los pueblos mismos hacen valorar su propia cultura: La diferencia como una relación y no como una oposición. Una relación en donde, por un lado, 
los distintos grupos oprimidos insisten en el valor positivo de su cultura y experiencias específicas, resultando, por tanto, cada vez más difícil para los grupos dominantes mostrar sus normas como neutrales y universales; y por el otro lado, esas diferencias nos ayudan a reconocer y reconocernos en nuestra propia identidad.

Esto, en el caso de los chuj, parece estarse encaminando y será todavía más factible en la medida que los propios padres de familia, como lo expresaron, asuman su responsabilidad y la posibilidad de trasformar la escuela en sus comunidades hacia una buena escuela, en la que haya buenos maestros, comprometidos y que enseñen orientando a las presentes y futuras generaciones con base en el conocimiento cultural del propio pueblo chuj.

Ofrecer un espacio de diálogo, más allá de obtener las representaciones sociales sobre la educación escolar, nos ofrecía una oportunidad de reflexión, de articulación de la memoria y la esperanza. De esta manera, muchas de las personas con quienes conversamos expresaron convicción por un futuro, para sí y para sus hijos, para la comunidad y el pueblo, basado ya no en la educación escolar, sino en los recursos propios; en la convicción de que en la dinámica propia del ámbito escolar, de interacción con otras culturas, lo fundamental es no perder lo propia. No obstante esta disposición favorable, desde su propia experiencia el pueblo chuj debe mantenerse, como hasta ahora, atento a lo que denuncia Schmelkes (2005: 2), y que en su momento fue una autocrítica:

La existencia y perpetuidad del pensamiento colonizado está a cargo de las mismas instituciones gubernamentales del país encomendadas de promover una educación intercultural, para resguardar celosamente los intereses del grupo hegemónico dominante.

Esto, como se ha expuesto, es percibido y denunciado por los chuj, quienes reciben en sus comunidades programas que, teniendo la obligación de considerar, respetar y fortalecer la cultura del pueblo con que trabajan, ${ }^{4}$ no han dado prácticamente ninguna señal ni mucho menos algún fruto al respecto. Finalmente debemos decir que no es sólo el reclamo que desde este rincón del país estarían articulando los chuj, sino que es la propia Constitución 
Política de los Estados Unidos Mexicanos, en su artículo 2, inciso B, fracción II, la que, además de garantizar la educación bilingüe e intercultural, establece la obligación del Estado por:

Definir y desarrollar programas educativos de contenido regional que reconozcan la herencia cultural de sus pueblos, de acuerdo con las leyes de la materia y en consulta con las comunidades indígenas.

Sería alentador que en un futuro no muy lejano un estudio semejante entre los chuj expresase nuevas y alentadoras representaciones sociales sobre la educación escolar. 


\section{BIBLIOGRAFÍA}

Abric, Jean Claude, 2001, «Las representaciones sociales: aspectos teóricos», en Prácticas sociales y representaciones, dirigido por Jean Claude Abric, Filosofía y cultura contemporánea, Ediciones Coyoacán y Embajada de Francia, México, pp. 195-214.

Díaz, Raúl y Graciela Alonso, 1998, «La dimensión «mundo» de la globalización y las identidades culturales», 1er. Congreso virtual de Antropología y Arqueología, Universidad Nacional del Comahue. Neuquén, Argentina, en http://www.naya.org.ar/congreso/ponencia1-5.htm [consulta: 22 de agosto de 2010].

Doise, Willem, Alain Clémence y Fabrice Lorenzi-Cioldi, 2005, Representaciones sociales y análisis de datos, Antologías Universitarias, Instituto Mora, México.

Duveen Gerard y Barbara B. Lloyd, 2003, «Un análisis semiótico del desarrollo de las representaciones sociales de género», en Representaciones sociales. Problemas teóricos y conocimientos infantiles, compilado por José Antonio Castorina, Gedisa, Barcelona, pp. 4163.

Foucault, Michel, 1970, El orden del discurso, Tusquets, Barcelona.

1976, Vigilar y castigar, Siglo XXI, México.

Goldmann, Lucien, 1976, Cultural Creation in Modern Society, Telos Press, Saint Louis Missouri.

Grize, Jean-Blaiss, Pierre Vergès y Ahmed Silem, 1987, Salariés face aux nouvelles technologies. Vers une approche socio-logique des représentations socials, Centre National de la Recherche Scientifique, Paris. 
Jodelet, Denise, 1986, «La representación social: fenómenos, concepto y teoría», en Psicología social II, editado por Serge Moscovici, Paidós, Barcelona, pp. 469-506.

2000, «Representaciones sociales: contribución a un saber sociocultural sin fronteras», en Develando la cultura. Estudios en representaciones sociales, coordinado por Denise Jodelet y Alfredo Guerrero, Facultad de Psicología, Universidad Nacional Autónoma de México, México, pp. 7-30.

Limón Aguirre, Fernando, 2008, «La ciudadanía del pueblo chuj en México. Una dialéctica negativa de identidades», Revista Alteridades, año 18, n. 35, pp. 85-98, Universidad Autónoma Metropolitana-Xochimilco. México.

2008b, «Alteridad y autoridad. Palabra y esperanza entre los chuj», en Movimientos Sociales del Siglo XXI. Diálogos sobre el Poder, coordinado por Ricardo Martínez, Fundación Editorial el perro y la rana, Caracas, pp. 187-205.

2009, «Aproximación etnográfica a los chuj mexicanos. Esbozos de su conocimiento cultural», en Sociedad y desigualdad en Chiapas. Una mirada reciente, editado por Jorge Luis Cruz y Austreberta Nazar, El Colegio de la Frontera Sur, San Cristóbal de Las Casas, Chiapas, pp. 92-125.

2009b, Historia chuj a contrapelo. Huellas de un pueblo con memoria, El Colegio de la Frontera Sur, Consejo Estatal de Ciencia y Tecnología de Chiapas, Tuxtla Gutiérrez, México.

López, Luis Enrique, 2000, «La cuestión de la interculturalidad y la educación latinoamericana», Seminario sobre prospectivas de la Educación en la región de América Latina y el Caribe, organizado por la UNESCO en Santiago de Chile, en http://www.aulaintercultural.org/IMG/pdf/lopez-unesco.pdf [consulta: 22 de agosto de 2010]. 
Maldonado, Benjamín, 2004, Lo sobrenatural en el territorio comunal. Propuestas para el desarrollo de la geografía simbólica en la educación intercultural de Oaxaca, Instituto Estatal de Educación Pública en Oaxaca, México.

Mora, Martín, 2002, «La teoría de las representaciones sociales de Serge Moscovici», Revista Athenea Digital, n. 2, otoño, en http://antalya.uab.es/athenea/num2/mora.pdf [consulta: 22 de agosto de 2010].

Moscovici, Serge, 1979, El psicoanálisis, su imagen y su público, Huemul, Buenos Aires.

Palacios Gámaz, Ana V., 2009, «Los estudios de representaciones en las Ciencias Sociales en México: 1994-2007», Estudios sobre las Culturas Contemporáneas, v. XV, n. 29, pp. 91-109, Universidad de Colima, México.

Saldívar Moreno, Antonio y Bertha Rivera Lona, 2006, «Pobreza y educación», en Representaciones sociales de la pobreza en Chiapas, coordinado por Rolando Tinoco y Liliana Bellato, Secretaría de Desarrollo Social y El Colegio de la Frontera Sur, San Cristóbal de Las Casas, México, pp. 76-98.

Schmelkes, Silvia, 2005, «La interculturalidad en la educación básica», Conferencia presentada en el Encuentro Internacional de Educación Preescolar: Curriculum y Competencias, Organizado por Editorial Santillana, 21 y 22 de enero, México, se puede consultar en: http://www.amdh.com.mx/ocpi/documentos/docs/6/16.pdf

Tajfel, Henri, 1984, «Intergroup relations, social myths and social justice in social psychology», en The social dimension, v. 2, editado por Henri Tajfel, Cambridge University Press, Editions de la Maison des Sciences de l'Homme, Cambridge, pp. 695715 . 
Notas

${ }^{1}$ Este estudio contó con recursos de Fondos Concurrentes SEP-SEB-CONACyT y en él participaron activamente Griselda López Rivas, realizando su tesis de licenciatura en Sociología por la UNACH y Diego Pérez Hernández como traductor, facilitador y mediador cultural.

2 «Mudo» es el sinónimo de tonto. Es una palabra denigrante que expresa reclamo por incapacidad.

${ }^{3}$ Actualmente seguimos desarrollando en nuestra investigación una línea tendente a la elaboración de esta teoría fundamentada de la enseñanza a la chuj.

${ }^{4}$ Tanto SEF, como PECI y CONAFE, los programas que se aplican en las comunidades chujes, tienen en su mandato considerar y promover el idioma y la cultura de los pueblos indígenas en que realizan sus actividades educativas.

Fecha de recepción: 30 de agosto de 2010.

Fecha de aceptación: 14 de febrero de 2011. 